\title{
Attitudes Toward Bisexuality According to Sexual Orientation and Gender
}

Katherine M. Hertlein

Erica E. Hartwell

Fairfield University, ehartwell@fairfield.edu

Follow this and additional works at: https://digitalcommons.fairfield.edu/education-facultypubs Copyright 2016 Taylor and Francis. A post-print has been archived with permission from the copyright holder. This is an Accepted Manuscript of an article published by Taylor \& Francis in Journal of Bisexuality in 2016, available online: http://www.tandfonline.com/10.1080/ 15299716.2016 .1200510

\section{Peer Reviewed}

\section{Repository Citation}

Hertlein, Katherine M. and Hartwell, Erica E., "Attitudes Toward Bisexuality According to Sexual Orientation and Gender" (2016). GSEAP Faculty Publications. 126.

https://digitalcommons.fairfield.edu/education-facultypubs/126

\section{Published Citation}

Hertlein, Katherine M., Erica E. Hartwell, and Mashara E. Munns. "Attitudes Toward Bisexuality According to Sexual Orientation and Gender." Journal of Bisexuality (July 2016) 16(3): 1-22.

This item has been accepted for inclusion in DigitalCommons@Fairfield by an authorized administrator of DigitalCommons@Fairfield. It is brought to you by DigitalCommons@Fairfield with permission from the rightsholder(s) and is protected by copyright and/or related rights. You are free to use this item in any way that is permitted by the copyright and related rights legislation that applies to your use. For other uses, you need to obtain permission from the rights-holder(s) directly, unless additional rights are indicated by a Creative Commons license in the record and/or on the work itself. For more information, please contact digitalcommons@fairfield.edu. 
Running head: ATTITUDES BY SEXUAL ORIENTATION AND GENDER

Attitudes Toward Bisexuality According to Sexual Orientation and Gender

\author{
Katherine M. Hertlein \\ University of Nevada, Las Vegas \\ Erica E. Hartwell \\ Fairfield University \\ Mashara E. Munns \\ University of Nevada, Las Vegas
}




\begin{abstract}
Despite increasing support for lesbian and gay individuals, the same degree of tolerance has not extended to bisexual individuals, and bisexual invisibility and biphobia are continuing problems that affect the mental health and well-being of bisexual people. There is evidence that attitudes toward bisexual people may vary by one's own sexual orientation or gender. In the present study, we examined differences in attitudes toward bisexual people by sexual orientation and gender. We also asked bisexual participants to describe their experiences of being stigmatized. This study found significant effects for sexual orientation but not for gender; specifically, heterosexual participants reported significantly more biphobia and negative bisexual attitudes than gay, lesbian, or bisexual participants. Further, bisexual participants reported feeling most stigmatized by heterosexual individuals. The results of this study indicate that attitudes toward bisexuality differ by sexual orientation but not by gender. The authors suggest implications for the mental health and well-being of bisexual people as well as possible interventions.
\end{abstract}

Keywords: bisexual, biphobia, sexual orientation, gender, sexual attitudes 
Attitudes Toward Bisexuality According to Sexual Orientation and Gender While research on bisexuality has expanded over the past several decades, bisexuality in general is still not entirely well understood or accepted in broader Western culture. Bisexuality is defined as "having attraction to more than one gender" (Barker et al. 2011, p. 3), and can encompass a variety of elements, such as those who experience romantic attraction regardless of gender, those who believe sexual orientation is fluid over the course of one's life, those who may predominately attracted to one gender but not exclusively, and those who acknowledge gender as fluid and non-binary (Barker et al. 2011). Despite increasing support for lesbian and gay individuals, tolerance has not extended to the same degree to bisexual individuals, and bisexual invisibility and biphobia are continuing problems (Alarie \& Gaudet, 2013; Elia, 2010) that affect the mental health and well-being of bisexual people (Eliason, 1997; Mays \& Cochran, 2001; McCabe, Bostwick, Hughes, West, \& Boyd, 2010; Ross, Dobinson, \& Eady, 2010).

There are a number of general misconceptions of bisexuality that appear to contribute to bi-negativity and biphobia. The most apparent of these are the numerous stereotypes of bisexual people that pervade the cultural narrative, including:

1. Bisexuality is just a phase, and bisexual individuals simply don't know what they want yet (Alarie \& Gaudet, 2013).

2. Bisexuality is a mask for homosexuality, especially among men (Brewster \& Moradi, 2010).

3. Bisexual people are less trustworthy and more likely to cheat on their partners (Alarie \& Gaudet, 2013).

4. Bisexual women are just experimenting and will go back to a man eventually (Hartman, 2013). 
5. Bisexual people experience less prejudice than gays and lesbians and enjoy more heterosexual privilege (Elia, 2010).

6. Bisexual people (especially men) are more prone to STDs and HIV due to their presumed promiscuity (Elia, 2010).

These stereotypes continue to alienate bisexual people from their heterosexual and lesbian/gay counterparts and make it harder for bisexual individuals to build lasting friendships and romantic relationships (Li, Dobinson, Scheim, \& Ross, 2013). Likewise, although bisexual people are considered part of the broader LGB population, some would argue that this association is more restricted and less beneficial than for lesbian and gay members (Obradors-Campos, 2011).

Several authors have suggested that people's discomfort with bisexuality - and the negativity and biphobia that stem from it - are a result of society's conceptualization of sexual orientation as an either/or proposition (Elia, 2010; Hartman, 2013; Obradors-Campos, 2011). Given our culture's dichotomous perception of gender and orientation, sexual orientation is typically determined by the relation of one's own gender to that of one's partner (Hartman, 2013). Thus, bisexual individuals are viewed as either heterosexual or gay/lesbian, depending on their current partner, which is in contradiction to how they view themselves (Galupo, 2011). This misconception invalidates and marginalizes bisexuality as a distinct orientation by making it invisible. From this view, biphobia is the result of heterosexism and an endorsement of strict male/female, straight/gay dichotomies. Bisexual individuals challenge this rhetoric and society's existing system of order, which creates dissonance and discomfort in individuals who adhere to these dichotomies (Elia, 2010; Obradors-Campos, 2011). 
There is evidence that attitudes towards bisexuality may vary depending on the gender of the bisexual person. Prior research suggests that female bisexuality is considered more socially acceptable than male bisexuality (Alarie \& Gaudet, 2013). One reason for this difference is because of the aforementioned stereotype, that bisexual men are simply "masking" homosexuality, and thus these individuals tend to be grouped in with gay males, who are often viewed more harshly than lesbian or bisexual women. This negative attitude toward male samesex attraction and behavior is a result of the Western notion that masculinity is tied to heterosexuality, and that attraction to other males is antithetical to a masculine identity (Flanders \& Hatfield, 2013). Thus, bisexual men may experience greater stigma because they are assumed to be gay and, therefore, not masculine.

Conversely, female bisexuality may be more acceptable because it is assumed to be a performance put on by women who are actually heterosexual. This is called performative bisexuality: female same-sex behavior that is encouraged by and directed at a heterosexual male audience (Fahs, 2009; Flanders \& Hatfield, 2013). Although women who are engaging in performative kissing or touching may actually be exploring their own sexuality (Esterline \& Galupo, 2013), on-lookers typically view them as heterosexual, and not bisexual or lesbian (Lannutti \& Denes, 2012). This phenomenon is commonly depicted in popular media, including television, film, and pornography. One example is the character of Kate Veatch in the movie, DodgeBall: A True Underdog Story (2004), who is pursued by the male protagonist while other characters joke that — based on stereotypes — she is probably a lesbian. At the end of the film, she kisses another woman in front of the male protagonist and then announces that she is bisexual. The message is that she will "perform" her bisexuality for a male audience, but is ultimately still sexually available to men. While depictions like this provide visibility of female bisexuality, they 
also reinforce the troubling stereotype that women engage in same-sex behavior only for the pleasure of men and not as an expression of their own sexuality.

Attitudes toward bisexuality are consistent with common double standards for male and female sexuality in general. For instance, Boyer and Galupo (2015) found that in their sample, different-sex casual sex was encouraged for men, but discouraged for women. Conversely, samesex behavior was viewed negatively for men, but encouraged for women. Thus, while performative bisexuality is not considered disconfirmation of a woman's heterosexuality, bisexual behavior in men is more likely to be construed as homosexuality. In other words, bisexual men are often assumed to be gay, while bisexual women are often assumed to be straight. In both scenarios, the individuals' bisexuality is being dismissed and marginalized. The question of who marginalizes bisexual identities has frequently been examined through the lenses of sexual orientation and gender.

\section{Heterosexual Attitudes Toward Bisexuality}

The attitudes of heterosexual individuals toward bisexuality may vary by their own gender as well as the gender of the bisexual person. Past studies have suggested that heterosexual men tend to have stronger heterosexist attitudes due to the pressure to present themselves as masculine or "real men" (Anselmi, Voci, Vianello, \& Robusto, 2015). Heterosexual individuals show a strong preference for heterosexuality, potentially due to the need to protect the self-image of the in-group. Eliason (1997) reported a 50-50 split in heterosexual college students' attitudes toward bisexual individuals. Half of participants viewed bisexuality favorably, while half viewed it as unacceptable. This effect, however, was moderated by gender; $61 \%$ of respondents viewed male bisexuality as negative, while a smaller margin viewed female bisexuality negatively. Another finding of Eliason's study was that the majority of heterosexual students surveyed did 
not endorse the idea that people can be born bisexual, reinforcing the belief that bisexuality is a transitory state. In addition, a few studies have consistently found heterosexual men are more likely to have negative attitudes toward bisexual men as compared to heterosexual women, and view bisexual women more favorably than heterosexual women view them (Herek, 2002; Yost \& Thomas, 2012).

\section{Gay and Lesbian Attitudes Toward Bisexuality}

Gay and lesbian attitudes toward bisexuality appear to be more complex than those of heterosexual individuals, and seem to be determined more significantly by gender. For instance, there appears to be more conflict between lesbians and bisexual women than between gay and bisexual men (Alarie \& Gaudet, 2013; Elia \& Eliason, 2012). Anselmi et al. (2015) found that gay men held weaker bias toward bisexuality than heterosexual men, but lesbian women showed equal implicit and higher explicit bias compared to heterosexual women. In other words, gay men were less biphobic than straight men, whereas lesbians were just as, if not more, biphobic than straight women. This may be, in part, because of the perceived privilege of bisexual women who have the ability to marry men or to "pass" as straight in the broader culture (Elia \& Eliason, 2012; Hartman, 2013). Alarie and Gaudet (2013) found that many gay men considered bisexuality to be a transitional phase for younger gay men. In contrast, they found that many lesbians viewed bisexual women as heterosexual and their bisexuality as performative. In another study, bisexual women indicated they did not feel that they fit in wider society nor did they feel they fit in the sexual minority groups. Their experience was that their bisexuality was categorized by lesbian women as being synonymous with hypersexual and that it was dismissed as being an indecisive position (Hayfield, Clarke, \& Halliwell, 2014). Mohr and Rochlen (1999) found that $32 \%$ of their gay and lesbian sample said that they would not date a bisexual person 
largely due to their perception of bisexual individuals as unstable or unsure of themselves. A belief in the instability of bisexuality seems to exist among both gay men and lesbians.

\section{Bisexual Attitudes Toward Bisexuality}

Less extensively studied are bisexual people's own self-perceptions and internalized biphobia (Israel \& Mohr, 2004). Obradors-Campos (2011) argued that most bisexual individuals experience internalized biphobia, and Herek et al. (2009) found that bisexual individuals experience higher levels of self-stigma than gay or straight individuals. This higher self-stigma may result in more identity confusion and less sense of belonging (Anselmi et al., 2015). In one study, participants who expressed bisexual behavior or attraction still frequently denied the existence of life-long bisexuality, reflecting the stereotype that bisexuality is unstable or just a phase (Alarie \& Gaudet, 2013). The minority stress framework (Meyer, 2003) argues that internalized stigma, such as internalized biphobia, can lead to psychological distress. In fact, research has consistently confirmed the relationship between biphobia and the adverse mental health and well-being of bisexual people (McCabe, Bostwick, Hughes, West, \& Boyd, 2010; Ross, Dobinson, \& Eady, 2010), including greater risk for suicidal ideation, substance use and abuse, fewer friends and greater isolation (Lea, de Wit, \& Reynolds, 2014; Lewis, Kholodkov, \& Derlega, 2012; Morandini, Blaszczynski, Dar-Nimrod, \& Ross, 2015). Parental rejection, which may be the result of social stigma and can contribute to internalized issues, s particularly contributive to depressive symptoms for girl who identify as bisexual ( Oldehinkel, Kretschmer, Veenstra, Dijkstra, \& la Roi, 2016).

Although bisexual people may experience and internalize stigma from the larger society, those individuals do not necessarily apply those same stereotypes to other bisexual people. A recent study found that bisexual participants did not perceive other bisexual people to be less 
decisive, less capable of monogamy, nor more focused on sex than heterosexual or gay/lesbian individuals (Burke \& LaFrance, 2016). This study, however, was unique in its focus on how bisexual people see themselves as a group. Most research to date (e.g., Lea, de Wit, \& Reynolds, 2014; Lewis, Kholodkov, \& Derlega, 2012) has investigated sexual minorities as a whole and compared attitudes and perceptions of bisexual to gay and lesbian participants. Examining the biases and in-group perceptions of bisexual people is critical to uncovering social attitudes that might otherwise go unexamined (Carr, 2011; Macdonald, 2000).

\section{Current Study}

This study attends to two important gaps in the research regarding biphobia and attitudes toward bisexuality: 1) few studies examine attitudes by both sexual orientation and gender, and include bisexual individuals' attitudes towards their own group; 2) few studies examine bisexual people's experiences of stigma according to the sexual orientation and gender of the other person. It is important to address these gaps because of the strong connection between stigma and mental health (Meyer, 2003). Bisexual people identify multilevel barriers to emotional wellbeing: societal, interpersonal, and individual (Ross, Dobinson, \& Eady, 2010). This study assessed two levels of stigma - societal, based on dominant beliefs and biases, and interpersonal, based on interactions with other people - as reported by in-group (bisexual) and out-group (straight and gay/lesbian) members. In the present study, we employed mixed methods to examine two research questions:

1. Do individuals report different attitudes toward bisexuality according to sexual orientation and gender?

2. Do bisexual individuals perceive different attitudes from others based on sexual orientation and gender? 


\section{Methods}

\section{Participants}

Participants were recruited from undergraduate courses (lower-division personal growth courses and upper-division human services theory courses) at a large, metropolitan university in the southwestern U.S. as well as other online communities across the U.S. The total sample included 473 individuals, ranging in age from 18 to 78 , with an average age of 29.77 ( $S D=$ 11.81). We asked participants in an open-ended format to describe their gender. For the most part, participants identified with the gender binary with 161 (34.2\%) self-reporting as male, 305 $(64.8 \%)$ self-reporting as female, and 5 reporting as “other". Other responses included "female leaning toward more masculine", "cisgender", “fluid”, and "non-binary". We asked two different questions regarding attraction. First, we asked participants to choose only one answer with whom they had a general attraction. In response to this question, a majority of the sample $(70.2 \%, n=$ 332) reported general attraction to a different sex or gender, while $7.4 \%(n=35)$ indicated a general attraction to their same sex or gender. One quarter of the sample $(n=101,21.4 \%)$ reported being attracted to more than one gender. And consistent with literature on the prevalence of asexuality, $1.1 \%(n=5)$ reported no attraction to any sex or gender.

Most participants had completed some college $(59.0 \%, n=207)$. Approximately $20.8 \%$ $(n=73)$ had a bachelor's degree. Ten percent $(n=35)$ had a masters and $3.7 \%(n=13)$ had a doctorate. Finally, 6.6\% $(n=23)$ had a high school degree. The remaining 122 participants did not respond to this question. Half of the sample $(57.3 \%, n=203)$ indicated they were White; 12.7\% $(n=45)$ indicated Hispanic/Latino/Spanish origin. Eleven percent $(n=41)$ indicated they were Black; 8.8\% $(n=31)$ indicated they were Asian; and 7.6\% $(n=27)$ indicated their race as 
“Other". The remainder $(n=119)$ did not respond to this question. After cases with missing data were omitted, 411 participants' responses were used in the analysis.

\section{Measures}

The survey itself contained 147 items, including demographics, the Biphobia Scale (Mulick \& Wright, 2002), 58 author-organized items created from a series of previously published scales, and open-ended questions asking about bisexual participants' experiences of stigma.

Biphobia. The Biphobia Scale is a 30-item scale developed by Mulick and Wright (2002; 2011) to assess attitudes toward bisexual individuals. Responses are given on a 7-point scale from not at all true about me to very true about me for a possible total score of 210 . In previous research it has been deemed reliable (Mulick \& Wright, 2002; 2011). The present study yielded Cronbach's $\alpha$ of .887 .

Bisexual Attitudes. The Bisexual Attitudes Scale began with 58 author-organized items that assessed knowledge, descriptions, and judgments about bisexuality and bisexual individuals. We selected items from other inventories assessing biphobia, including items from the Alarie and Gaudet (2013) scale, Cox, Bimbi, and Parsons (2013), Obradors-Campos (2011), Hartman (2013), Elia (2010), Ochs (2011), Eisner (2013), Mohr and Rochlen (1999), and See and Hunt (2011). See Table 1 for a listing of items according to publications.

Once data collection was complete, an exploratory factor analysis with a Varimax rotation revealed that 38 of the 58 items loaded onto one factor. These individual items with the means, standard deviations, and factor loadings can be found in Table 1. The Cronbach's $\alpha$ for this scale was .953 . 
Bisexual Experiences of Stigma. In order to gain a fuller picture of how bisexual individuals experience stigma, those who identified as being attracted to more than one gender were asked three open-ended questions:

- Is it ever easier or preferable to not self-identify your sexual orientation in certain situations or with certain people? If so, in what kind of circumstances?

- Can you describe a situation where you felt someone treated you better because of your sexual identity?

- Can you describe a situation where you felt someone treated you worse because of your sexual identity?

\section{Procedures}

This study was approved by the university's institutional review board. As aforementioned, the purpose of this study was to examine differences in biphobia based on gender and sexual orientation. To answer this question, we recruited participants to complete an online survey assessing attitudes. Data were analyzed using a 2x3 factorial MANOVA. Gender served as an independent variable with two levels (male, female). Sexual orientation was the other independent variable with three levels (attraction to different sex, attraction to same sex, and attraction to more than one sex or gender). Due to the low number of asexual participants (n =5), they were excluded from analysis. The dependent variables were the Biphobia scale (Mulick \& Wright, 2002), and the author-organized Bisexual Attitudes Scale.

Open-ended responses were coded using a content coding method, where the first author and a team of three master's level students read and marked repeated words across responses within each single question (Emerson, Fetz, \& Shaw, 1995). The first author and team then met 
and read the common words they each saw and came to agreement as to what common themes were articulated.

\section{Results}

\section{Biphobia Scale and Bisexual Attitude Scale}

We conducted our analysis using SPSS version 21. We first recoded the items on the Biphobia scale so that each item was in the same direction. A higher score indicates higher biphobia. The scores on both scales are presented in Table 2 according to participant's gender and sexual orientation. We also ran a Pearson's $r$ correlation to determine how closely associated our Bisexual Attitude Scale was to the Biphobia Scale (Mulick \& Wright, 2002). The scales were correlated, $r=.857, p=.000$, satisfying the requirement that independent variables in a MANOVA be correlated.

-Insert Table 2 About Here

In the MANOVA, there was a not a statistically significant interaction effect between gender and sexual orientation type on the combined variables, $F(4,704)=1.603, p=.1172$ Pillai's Trace $=.018, \eta_{\mathrm{p}}^{2}=.01$. There was no significant main effect for gender in either scale: the Biphobia Scale, $F(2,352)=.1 .133, p=.323, \mathrm{\eta}_{\mathrm{p}}^{2}=.007$ nor the Bisexual Attitude Scale $F(2$, $352),=1.022, p=.361, \eta_{\mathrm{p}}^{2}=.006$. There was, however, a significant main effect for sexual orientation for both the Biphobia Scale, $F(2,352)=13.409, p<.001, \mathrm{\eta}_{\mathrm{p}}^{2}=.067$, and the Bisexual Attitude Scale, $F(2,352)=9.369, p<.001, \mathrm{\eta}_{\mathrm{p}}{ }^{2}=.051$. A Tukey's HSD posthoc analysis revealed that on both scales, heterosexual participants scored higher (were more biphobic or had more negative attitudes) than bisexual participants $(p<.001)$. Heterosexual participants also scored higher than gay/lesbian participants on both scales but at different confidence levels. On the Biphobia Scale, they were significantly more biphobic at the .05 level, 
whereas on the Bisexual Attitudes Scale, their reported attitudes were more negative at the .10 level. There were no statistically significant differences between lesbian/gay and bisexual participants. The results of the post hoc analysis are presented in Table 3.

-Insert Table 3 About Here-

\section{Bisexual Experiences of Stigma}

Responses to the open-ended questions are presented here according to question and themes identified by and agreed upon by all coders. As female participants comprised over $60 \%$ of our sample (33 men reported they were bisexual as compared to 67 women in the sample), there are more quotes from female participants than male participants in this section.

\section{Is it ever easier or preferable to not self-identify your sexual orientation in certain}

situations or with certain people? Participants indicated it was easier not to identify: 1) in work or professional situations; 2) around non-affirmative individuals, such as certain straight people and some family members; and 3) in situations where it was irrelevant. However, for many participants, the feedback was that it was easier to not identify in almost every situation. Our data were replete with comments like, "This is true in pretty much every circumstance." As one female participant stated,

Almost always its easier to not self-identify. I don't need to justify my existence or explain myself to anyone. It also just doesn't really come up much in day to day life.

Where I come from you don't go around announcing your sexuality as a matter of course. It really only comes up when introducing a partner of the same gender to others. If I am at the point of making introductions then I am comfortable identifying as bi. Otherwise what happens in my bed should stay there. 
Having to educate others was also a deterrent in identifying as bisexual. One female participant stated "It's easier to not self-identify with straight people, with new people, with people who wonder what it means to be bisexual and be married." Another male participant stated: 'It's almost always better that I don't self-identify because I don't feel like educating others all the freaking time". Another female participant stated, "it's difficult explaining your sexual orientation to people, mostly heterosexual, that do not fully understand the concept of being attracted to more than one gender."

Deciding to disclose in safe contexts and with safe people was another theme that emerged. Several participants discussed specific groups of people that felt unsafe. One such group consisted of straight individuals. One male participant noted "Yes, the LGBTQ, fetish/BDSM, and raver communities are far more accepting of bisexual males than the mainstream heterosexual/cisgender communities. People stereotype bisexuals as lecherous, unfaithful, and self-hating." Comments representing this included, "It's easier not to selfidentify with straight people", "not with straight groups", “especially with straight people who have difficulty understanding." Other people who were deemed unsafe were those who were religious, as evidenced by statements such as "those who are religiously affiliated", "[in] religious settings I feel no need to mention my sexuality at all," and people perceived as closeminded such as family members who were "highly reactive", "parents", and "people who seem judgmental or opinionated."

In some circumstances, the ease of not disclosing was related to current relationship context. As one female participant noted, "It's always easier not to say anything. I'm married at this point so my sexual attraction to women are no longer of consequence to anyone outside my marriage." Another female echoed this statement by saying: "Even if somebody was clearly 
supportive of bi people... I don't see what difference it would make to tell them. I am married, so at this point I'm probably never going to act on my attraction to the same gender."

Another theme that emerged was participants responding that while they may not reveal their orientation broadly, they would reveal it should a relationship become close. One female participant discussed the complexity of the issue by saying:

With romantic partners (i.e., queer females), I've found that it's less problematic to just not identify as bisexual. With queer men, however, I've found that they don't typically have as much regard (in general) for queer women's sexual orientation (which is the total opposite of how I've seen them respond toward males who identify as bisexual). Among heterosexuals, admitting such information often results in my queer community membership being called into question, which makes me feel uncomfortable because even if I weren't a queer woman, I still would not appreciate or enjoy being associated with the tyrannical, misogynistic, \& dichotomizing identity known as 'heterosexual.'

For others, the fact that they were bisexual prevented them from ever disclosing their identity. For example, one female participant stated "I never identify - no matter what I'm right down the middle." Another female participant stated "I personally haven't come out to anyone, but I am nervous to not be taken seriously for being bisexual.” For both of these participants, being "middle of the road" in their status prevented the disclosure because of the interpretation.

\section{Can you describe a situation where you felt someone treated you better because of}

your sexual identity? One of the most consistently emerging themes as to when participants thought they were treated better because of their sexual orientation was when they were in their LGB community. This was supported by both male and female participants saying they were treated better "around other lesbians", "at gay pride", "at a gay club", or "at a party with friends 
that were mostly gay." Other participants stated: "being surrounded by other LGBTQ, there is a sense of understanding and you feel more welcome"; "I am preferred amongst gays as we are similar"; "most gay people are nicer to me if they find out I'm bisexual"; "I've met other bisexuals who were happy to know I was one too, and they were friendly." Another male observed, "I am treated really nicely in social justice circles because I am the token bisexual male, and they clearly want me to feel more comfortable." Other circumstances in which participants noted being treated better tied directly to some of the misconceptions about bisexual people. For example, one female participant noted, "I think I had an easier time getting guys even though I am quite large since they figured bisexuality meant a threesome was in their future." Another woman stated: "I have had men buy me drinks before or do special favors for me because it was a turn-on to them."

\section{Can you describe a situation where you felt someone treated you worse because of}

your sexual identity? Circumstances in which participants were treated worse often included unaccepting romantic partners. For example, one female participant stated "I have been ignored or shunned because of it. Particularly by girls who I was interested in dating but they said they wouldn't date me because I would eventually 'leave them for a man' which was incredibly offensive." Another female participant stated: "A past relationship, he didn't take it serious that I was attracted to women" and another male participant agreed: "When my partner discovered my sexual identity, she reacted negatively."

Stereotypes of being bisexual, such as being confused or promiscuous also prevailed and were associated with negative reactions. One female participant stated "I've been told that I'm just confused, that all girls think they're bisexual when they're young, and I've been asked why it matters if I'm married to a man." Another female stated "Most straight people have negative 
perceptions of bisexuals. Many women think either I'm looking at them sexually, and most people think I shouldn't want or have a monogamous heterosexual relationship because I am also attracted to women." One female participant summed up both by stating: "People have tried to force me into a threesome without my consent before. That was the worst time. Other than that, people have insinuated I am bi to get attention or because I am confused." A male participant had a similar report:

Several heterosexuals (male and female) have treated me as not suitable for a relationship, but have attempted to seduce me because they assume as a bisexual male I will sleep with anyone, and perform any sexual activity they want. This is dehumanizing because it becomes about their pleasure rather than both of ours, and reduces me to little more than a sex toy (Straight males that [sic] want to have me perform oral and/or receive anal sex are especially guilty of this).

Finally, while not mentioned as frequently as some of the other categories, a few participants did acknowledge that their negative experiences were tied to gay/lesbian individuals. One male participant exemplified this by saying:

Gay people will tell me I'm not really one of them if I reveal my identity. They don't understand the continuum of sexuality any more than straight people do. On occasion I've run into a very bigoted straight person as well, but I've felt much more flack from the gay community when I try to participate in theoretically GLBT life in my community. I sort of gave up trying with the queers.

Another participant shared her account:

"I have had a few lesbians act hostile towards me when they find out I have dated cisgender men and/or that I'm in a relationship with a transgender man. One told me, 
trying to be sympathetic I think, that 'it must be hard to be thrown out of the lesbian community.' I was unaware I had been until that conversation!"

\section{Discussion}

Overall, the quantitative and qualitative results of this study indicated that attitudes about bisexuality differ largely by sexual orientation but not by gender. This confirms the original findings from the development of the Biphobia Scale (Mulick \& Wright, 2002)—which showed significant effects for sexual orientation but not gender - but contradicts other research that found more negative attitudes in heterosexual men than in heterosexual women (Anselmi et al., 2015) and in lesbian women than in gay men (Alarie \& Gaudet, 2013; Anselmi et al., 2015; Elia \& Eliason, 2012).

\section{Quantitative Findings}

The quantitative findings of this study confirmed previous research that heterosexual individuals tend to have more biphobic or binegative attitudes than do gay/lesbian or bisexual individuals (Alarie \& Gaudet, 2013; Elia \& Eliason, 2012). Examples of such attitudes include believing bisexual individual should be discriminated against, make one nervous, that their behavior is unacceptable, and are untrustworthy. Our findings, however, contradicted other research in which gay/lesbian participants were more biphobic than bisexual participants (Alarie \& Gaudet, 2013; Anselmi et al., 2015; Elia \& Eliason, 2012; Hartman, 2013; Mohr \& Rochlen, 1999). There were no significant differences between gay, lesbian, or bisexual individuals in this study. This could be due to a number of possible factors. First, the subsample of gay/lesbian participants in this study was relatively small; therefore, their responses may not be representative of the larger population or there may not have been enough gay/lesbian participants to detect significant differences in other areas. Second, this study sample was 
relatively young, with the majority of participants between the ages of 20 and 40 . The more accepting views represented in this sample could be an indicator of greater acceptance of bisexuality among younger generations of gay and lesbian individuals (Doty, Willoughby, Lindahl, \& Malik, 2010).

Although not significantly different from gay/lesbian participants, bisexual individuals in this study had the lowest scores on both scales. This is in line with previous research that there is less in-group negativity among bisexual individuals than other sexual orientations (Anselmi et al., 2015). That is, they are less likely to stigmatize other bisexual people. There is much research in the field of social psychology that attempts to understand the root of in-group perceptions. Specifically, social identity theory (Tajfel \& Turner, 1986) posits that group members promote a positive view of their group in order to boost their own self-esteem. This is particularly beneficial to members of a stigmatized group (Frable, Platt, \& Hoey, 1998). Therefore, bisexual individuals may benefit from espousing a positive view of other bisexual people. It is also possible that bisexual individuals have a more nuanced understanding of bisexual identities, and are less prone to believing many of the cultural stereotypes surrounding bisexuality.

Although bisexual individuals may promote a positive view of bisexuality and hold fewer prejudices against other bisexual people, bisexual individuals often stigmatize themselves through internalized biphobia (Herek et al., 2009; Obradors-Campos, 2011). Research has demonstrated a clear connection between this internalized stigma and the mental and physical well-being of bisexual individuals (Eliason, 1997; Mays \& Cochran, 2001; McCabe, Bostwick, Hughes, West, \& Boyd, 2010; Ross, Dobinson, \& Eady, 2010). The discrepancy between 
bisexual individuals' views of themselves and of their bisexual peers is intriguing and certainly warrants further investigation.

\section{Qualitative Findings}

Our qualitative data confirmed previous research findings that bisexual individuals experience stigma in numerous social situations, and many participants reported that they are not out because of this. Responses also indicated that much of the negative treatment that bisexual individuals experienced was based on harmful stereotypes, such as the notion that bisexual people are promiscuous, confused, or seeking attention. These stereotypes often interfered with bisexual participants' ability to establish healthy relationships with either same- or different-sex partners (Li et al., 2013). Many bisexual participants reported difficulty in finding a romantic partner who understood or embraced their sexual identity. Instead, potential partners tended to oversexualize the participants, in some cases fearing their bisexual partners would be promiscuous while, in other cases, demanding promiscuity through group or same-sex sexual encounters. A few participants, both male and female, highlighted instances where they felt straight-identified men expected and encouraged this promiscuity of them, whereas female participants frequently described lesbian women's fear of this presumed promiscuity. This supports the research that heterosexual men often objectify bisexual women (Fahs, 2009; Flanders \& Hatfield, 2013) and extends it by demonstrating that they also, at times, objectify bisexual men. Further, this data supports research showing that same-sex partners may reject bisexual individuals based on the stereotype they are not trustworthy and their identities are not stable (Mohr \& Rochlen, 1999; Rust, 2000).

A salient theme regarding the bisexual identities of female participants arose across the open-ended response categories. Many bisexual women reported that, because they were married 
to straight men, they felt as though their bisexuality was either invisible or irrelevant. Several female participants reported that their bisexual identity had been questioned or dismissed by others because they were in a committed (and presumably monogamous) relationship with a man. Others felt as though their bisexual identity did not matter because they would not be able to act on their attractions to women. Conversely, several of the female participants also reported a sense of mistrust from lesbian women, who were convinced that their bisexual partners were actually straight or would inevitably leave them for a man. Therefore, regardless of the gender of a bisexual woman's partner, the assumption is that, in the end, she will prioritize relationships with men over relationships with women. This finding likely extends beyond this sample and is rooted in the larger patriarchal, heterocentric U.S. culture that values women in accordance with their relationship to men.

Beyond intimate relationships, our participants identified other people with whom they felt stigmatized, namely people who were heterosexual, conservatively religious, or judgmental. Participants often noted that their bisexual identity was not anyone else's business, particularly in professional situations. They also mentioned a fear of not being taken seriously. Overall, however, when asked to define groups that stigmatized their identity, participants were more likely to make distinctions based on sexual orientation than by gender. Beyond the oversexualizing of bisexual women by heterosexual men, our respondents did not identify meaningful differences in how they are treated by men versus women. Instead, they largely supported our quantitative findings that bisexual individuals experience more stigmatization by heterosexual individuals than by gay men or lesbians-even considering the instances of rejection by same-sex romantic partners. 
Combined with the knowledge of minority stress and the findings from our study on feelings of marginalization, it underscores the importance of attending to potentially adverse mental health issues. The participants both noted the demands/expectations put on them (i.e., the assumption that bisexuals are promiscuous) but also followed the expectations (for example, allowing themselves to participate in more varied sexual activities). In this way, those who are bisexual may experience society's expectations toward them as being treated as objects and feel the pressure to respond as objects. This objectification may then have implications for power in relationships - the person who is objectified has the least amount of power in the relationship. Therefore, future research may wish to address the experience of power in mixed-orientation relationships (as were some of our participants) or the perception of power for bisexuals in the LGB community.

\section{Implications}

Bisexual people identify multilevel barriers to emotional well-being: societal, interpersonal, and individual (Ross, Dobinson, \& Eady, 2010). This study assessed two levels of stigma: societal and interpersonal. Societal stigma is based in the dichotomy of gay and straight, which is arguably the basis for biphobia. Bisexual individuals experience societal stigma as invisibility, stereotypes portrayed in the media, and in common social assumptions about bisexuality (e.g., that it is a phase). Interpersonal stigma is experienced through unsupportive relationships with romantic partners, friends, family members, co-workers, and those seen as part of one's LGB community.

The results of this study indicate that the societal beliefs and interpersonal interactions with heterosexual people may have more impact on bisexual individuals. Therefore, efforts to reduce biphobia may be most impactful when geared toward the heterosexual population. While 
psychoeducational interventions exist for reducing homophobia (Tucker, 2006), only one has been tested to reduce biphobia (Perez-Figueroa, Alhassoon, \& Wang-Jones, 2013). In this study, the authors found that conveying factual information about bisexuality increased participants' beliefs in the stability of bisexuality as a sexual orientation. It did not, however, increase tolerance. The authors hypothesized that increasing tolerance, which is often an affective state, may take longer than a one-time intervention. We suggest that affective change may be best achieved through direct and personal interactions with bisexual people. Possible interventions may include intergroup dialogues, where individuals with varying sexual identities are able to have safe, collaborative dialogues about their experiences. These structured conversations have been to shown to improve relations across race and gender in higher education settings (Gurin, Nagda, \& Zuniga, 2013).

Although negative attitudes and biphobia were lower in the gay and lesbian sample than in the heterosexual sample, bisexual participants still reported experiencing interpersonal stigma from lesbian and gay friends and partners. Given that bisexual people are grouped with lesbian and gay people into the cultural concept of a LGB community, it may be beneficial to focus on reducing binegativity and fostering acceptance of bisexual people among gay men and lesbians. An increased sense of belonging among lesbians and gay men could lead to increased selfacceptance and self-esteem among bisexual people (Frable et al., 1998). In fact, research involving bisexual college students has shown that the more accepting their social networks were of their orientation, the less internalized binegativity they experienced (Sheets \& Mohr, 2009). Similarly, it may also be beneficial to focus on building community among bisexual people as their own identity group. To be sure, bisexuality is distinct from exclusive same-sex attraction in many ways and comes with its own challenges and rewards. Given their typically positive in- 
group perceptions (Burke \& LaFrance, 2006), bisexual individual's own self-perceptions may benefit from increased interaction with other bisexual people.

\section{Limitations}

Several limitations of this study should be noted. First, the study sample included a small number of gay/lesbian participants which could have obscured certain sexual orientation effects. For example, gay/lesbian participants were significantly less biphobic than heterosexual participants, which is to be expected. However, there were no significant differences between gay/lesbian and bisexual participants, which was not expected. It is possible that a larger subsample of gay/lesbian participants may have revealed different findings.

A strength of this study is the large bisexual sample, which is often a limitation of other studies (Brewster \& Moradi, 2010). The larger number of bisexual participants in this study is important for generalizability purposes but also for representation reasons. When studying bisexual people, it is important to base findings on a sufficient sample, particularly considering how frequently they are minimized or marginalized in society (Israel \& Mohr, 2004). Further, there are few studies on the in-group perceptions of bisexual people; by having a sufficient bisexual sample, this study can make a more meaningful contribution to that research gap.

It should also be noted that the measures used in this study employ the terminology, “opposite sex." Because these measures were chosen based on their established validity and reliability, their language was not changed. However, the authors note that the use of the word "opposite" when referring to sex or gender reinforces the notion of a gender binary — the assumption that there are only two sexes and two accompanying genders. The authors acknowledge the existence of multiple genders as well as the possibility of attraction to multiple 
genders and used this pluralistic language when constructing questions about attraction and orientation.

\section{Conclusion}

In this study, heterosexual individuals reported significantly higher biphobia and more negative attitudes about bisexuality than gay men, lesbian women, and bisexual individuals. There were no significant differences between gay/lesbian and bisexual individuals, although bisexual participants did have the lowest scores on both scales. More surprising, this study found no differences in attitudes toward bisexuality by the gender of the participant, contrary to other investigations. Bisexual individuals also reported more meaningful differences in how they are treated by heterosexual people and sometimes gay and lesbian people, than in how they are treated by men versus women. These findings have implications for interventions designed to reduce biphobia and binegativity. First, efforts should focus on increasing knowledge and acceptance in the heterosexual population through both education and interpersonal interactions. Second, efforts to foster more community among bisexual people and between bisexual and gay/lesbian people could result in a more positive self-image of bisexuality. Third, effective interventions to reduce bisexual stigma are crucial given the known negative effects of this stigma on the mental health and well-being of bisexual individuals. These might include using social marketing interventions (perhaps via social media) to directly target and reduce stigma associated with marginalized groups (Friedman et al, 2014). 


\section{References}

Alarie, M., \& Gaudet, S. (2013). "I don't know if she is bisexual or if she just wants to get attention": Analyzing the various mechanisms through which emerging adults invisibilize bisexuality. Journal of Bisexuality, 13(2), 191-214. doi: 10.1080/15299716.2013.780004

Anselmi, P., Voci, A., Vianello, M., \& Robusto, E. (2015). Implicit and explicit attitudes across genders and sexual orientations. Journal of Bisexuality, 15(1), 40-56. doi:10.1080/15299716.2014.986597

Barker, M., Richards, C., Jones, R., Bowes-Catton, H., Plowman, T., Yockney, J., \& Morgan, M. (2012). The bisexuality report: Bisexual inclusion in LGBT equality and diversity. Milton Keynes: The Open University Centre for Citizenship, Identities, and Governance.

Boyer, C. R., \& Galupo, M. P. (2015). Attitudes toward individuals in same-sex and cross-sex encounters: Implications for bisexuality. Journal of Bisexuality, 15(1), 57-68. doi:10.1080/15299716.2014.984371

Burke, S. E., \& LaFrance, M. (2016, April 11). Stereotypes of bisexual people: What do bisexual people themselves think? Psychology of Sexual Orientation and Gender Diversity. Advance online publication. http://dx.doi.org/10/1037/sgd0000168

Carr, C. (2011). Women's bisexuality as a category in social research, revisited. Journal of Bisexuality, 11, 550-559. doi: 10.1080/15299716.2011.620868

Cox ,S., Bimbi, D. S., \& Parsons, J. T. (2013). Examination of social contact on binegativity among lesbians and gay men. Journal of Bisexuality, 13(2), 215-228. doi: $10.1080 / 15299716.2013 .782596$ 
de Bruin, K., \& Arndt, M. (2010). Attitudes toward bisexual men and women in a university context: Relations with race, gender, knowing a bisexual man or woman and sexual orientation. Journal of Bisexuality, 10(3), 233-252. doi: 10.1080/15299716.2010.500955

Doty, N. D., Willoughby, B. B., Lindahl, K. M., \& Malik, N. M. (2010). Sexuality related social support among lesbian, gay, and bisexual youth. Journal of Youth and Adolescence, 39(10), 1134-47. doi: 10.1007/s10964-010-9566-х

Eisner, S. (2013). BI: Notes for a bisexual revolution. Berkeley, CA: Seal Press.

Elia, J. P. (2010). Bisexuality and school culture: School as a prime site for bi-intervention. Journal of Bisexuality, 10(4), 452-471. Doi: 10.1080/15299716.2010.521060

Elia, J. P., \& Eliason, M. J. (2012). A decade of the Journal of Bisexuality: Some notes on content and future directions. Journal of Bisexuality, 12(1), 4-12. doi:10.1080/15299716.2012.645690

Eliason, M. J. (1997). The prevalence and nature of biphobia in heterosexual undergraduate students. Archives of Sexual Behavior, 26(3), 317-326.

Esterline, K. M., \& Galupo, M. P. (2013). "Drunken curiosity" and "gay chicken": Gender differences in same-sex performativity. Journal of Bisexuality, 13(1), 106-121. doi: $10.1080 / 15299716.2013 .755732$

Fahs, B. (2009). Compulsory bisexuality? The challenges of modern sexual fluidity. Journal of Bisexuality, 9(3/4), 431-449. doi: 10.1080/15299710903316661

Flanders, C. E., \& Hatfield, E. (2013). Perceptions of gender and bisexuality: An exploration of the relationship between perceived masculinity, femininity, and sexual ambiguity. Journal of Bisexuality, 13(3), 374-389. doi:10.1080/15299716.2013.813418 
Frable, D. E. S., Platt, L., \& Hoey, S. (1998). Concealable stigmas and positive self-perceptions: Feeling better around similar others. Journal of Personality and Social Psychology, 74(4), 909-922. doi: 10.1037/0022-3514.74.4.909

Friedman, M. R., Dodge, B., Schick, V., Herbenick, D., Hubach, R., Bowling, J., ... Reece, M. (2014). From bias to bisexual health disparities: Attitudes toward bisexual men and women in the United States. LGBT Health, 1(4), 309-318. doi:10.1089/lgbt.2014.0005.

Galupo, M. P. (2011). Bisexuality: Complicating and conceptualizing sexual identity. Journal of Bisexuality, 11(4), 545-549. doi:10.1080/15299716.2011.620866

Gurin, P., Nagda, B. A., \& Zuniga, X. (2013). Dialogue across difference: Practice, theory, and research on intergroup dialogue. New York: Russell Sage Foundation.

Hartman, J. E. (2013). Creating a bisexual display: Making bisexuality visible. Journal of Bisexuality, 13(1), 39-62. doi:10.1080/15299716.2013.755727

Hayfield, N., Clarke, V., \& Halliwell, E. (2014). Bisexual women's understandings of social marginalisation: 'the heterosexuals don't understand us but nor do the lesbians'. Feminism \& Psychology, 24(3), 352. doi:10.1177/0959353514539651

Herek, G. (2002). Heterosexuals' attitudes toward bisexual men and women in the United States. The Journal of Sex Research, 39(4), 264-274. doi: 10.1080/00224490209552150

Herek, G. M., Gillis, J. R., \& Cogan, J. C. (2009). Internalized stigma among sexual minority adults: Insights from a social psychological perspective. Journal of Counseling Psychology, 56(1), 32-43. doi:10.1037/a0014672

Israel, T., \& Mohr, J. J. (2004). Attitudes toward bisexual women and men. Journal of Bisexuality, 4(1-2), 117-134. doi: 10.1300/J159v04n01_09 
Lannutti, P. J., \& Denes, A. (2012). A kiss is just a kiss? Comparing perceptions related to female-female and female-male kissing in a college social situation. Journal of Bisexuality, 12(1), 49-62. doi: 10.1080/15299716.2012.645716

Lea, T., de Wit, J., \& Reynolds, R. (2014). Minority stress in lesbian, gay, and bisexual young adults in australia: Associations with psychological distress, suicidality, and substance use. Archives of Sexual Behavior, 43(8), 1571-1578. doi:10.1007/s10508-014-0266-6

Lewis, R. J., Kholodkov, T., \& Derlega, V. J. (2012). Still stressful after all these years: A review of lesbians' and bisexual women's minority stress. Journal of Lesbian Studies, 16(1), 30. doi:10.1080/10894160.2011.557641

Li, T., Dobinson, C., Scheim, A. I., \& Ross, L. E. (2013). Unique issues bisexual people face in intimate relationships: A descriptive exploration of lived experience. Journal of Gay and Lesbian Mental Health, 17(1), 21-39. doi:10.1080/19359705.2012.723607

MacDonald, A. P. (2000). A little bit of lavender goes a long way: A critique of research on sexual orientation. In P. C. R. Rust (Ed.), Bisexuality in the United States: A social science reader (pp.24-30). New York: Columbia University Press.

Mays, V. M., \& Cochran, C. D. (2001). Mental health correlates of perceived discrimination among lesbian, gay, and bisexual adults in the United States. American Journal of Public Health, 91(11), 1869-1876. doi: 10.2105/AJPH.91.11.1869

McCabe, S. E., Bostwick, W. B., Hughes, T. L., West, B. T., \& Boyd, C. J. (2010). The relationship between discrimination and substance use disorders among lesbian, gay, and bisexual adults in the United States. American Journal of Public Health, 1000(10), 19461952. doi: 10.2105/AJPH.2009.163147 
Morandini, J. S., Blaszczynski, A., Dar-Nimrod, I., \& Ross, M. W. (2015). Minority stress and community connectedness among gay, lesbian and bisexual australians: A comparison of rural and metropolitan localities. Australian and New Zealand Journal of Public Health, 39(3), 260-266. doi:10.1111/1753-6405.12364

Mulick, P. S., \& Wright, L.W. (2002). Examining the existence of biphobia in the heterosexual and homosexual populations. Journal of Bisexuality, 2(4), 45-64. doi:10.1300/J159v02n04_03

Mulick, P. S., \& Wright, L. W. (2011). The biphobia scale a decade later: Reflections and additions. Journal of Bisexuality, 11(4), 453-457. doi:10.1080/15299716.2011.620486

Obradors-Campos, M. (2011). Deconstructing biphobia. Journal of Bisexuality, 11(2-3), 207226. doi:10.1080/15299716.2011.571986

Ochs, R. (2011). Why we need to “Get Bi”. Journal of Bisexuality, 11, (2-3), 171-175. doi: $10.1080 / 15299716.2011 .571983$

Oldehinkel, A. J., Kretschmer, T., Veenstra, R., Dijkstra, J. K., \& la Roi, C. (2016). Disparities in depressive symptoms between heterosexual and lesbian, gay, and bisexual youth in a dutch cohort: The TRAILS study. Journal of Youth and Adolescence, 45(3), 440-456. doi:10.1007/s10964-015-0403-0

Perez-Figueroa, A. M., Alhassoon, O. M., \& Wang-Jones, T. (2013). The effect of psychoeducation on attitudes toward bisexuality. Journal of Bisexuality, 13(3), 338-355. doi: $10.1080 / 15299716.2013 .813420$

Rust, P. C. (2000). Neutralizing the political threat of the marginal woman: Lesbians' beliefs about bisexual women. In L. Faderman \& L. Gross (Eds.), Bisexuality in the United States (pp. 471-497). New York: Columbia University Press. 
See, H., \& Hunt, R. (2011). Bisexuality and identity: The double-edged sword: Stonewall research into bisexual experience. Journal of Bisexuality, 11(2-3), 290-299. doi: $10.1080 / 15299716.2011 .571995$

Sheets, R., Jr., \& Mohr, J. (2009). Perceived social support from friends and family and psychosocial functioning in bisexual young adult college students. Journal of Counseling Psychology, 56(1), 152-163.

Stiller, B., (Producer), Cornfeld, S. (Producer), \& Thurber, R. M. (Director). (2004). DodgeBall: A true underdog story [Motion Picture]. United States: $20^{\text {th }}$ Century Fox.

Tajfel, H., \& Turner, J. (1986). The social identity theory of intergroup behavior. In S. Worchel \& W. G. Austin (Eds.), Psychology of Intergroup Relations, (2 ${ }^{\text {nd }}$ ed) (pp. 7-24). Chicago; Nelson-Hall Publishers. Tucker, E. W. (2006). Changing heterosexuals' attitudes toward homosexuals: A systematic review of the empirical literature. Research on Social Work Practice, 16(2), 176-190. doi: 10.1177/1049731505281385

Yost, M. R., \& Thomas, G. D. (2012). Gender and binegativity: Men's and women's attitudes toward male and female bisexuals. Archives of Sexual Behavior, 41(3), 691. doi:10.1007/s10508011-9767-8 


\section{Table 1}

Factor loadings, means, and standard deviations for Bisexual Attitudes Scale

\begin{tabular}{|c|c|}
\hline Author & Item \\
\hline Obradors-Campos & $\begin{array}{l}\text { I am uncomfortable talking about relationships with a bisexual person because I do not know how to talk to } \\
\text { or refer to their partner(s) }\end{array}$ \\
\hline Obrados-Campos & Bisexuality exists. \\
\hline Hartman & $\begin{array}{l}\text { If my partner came out to me as bisexual, I would believe that he/she would want an open relationship or } \\
\text { threesomes }\end{array}$ \\
\hline Elia & Bisexual people are more inclined to cheat on their partners. \\
\hline $\begin{array}{l}\text { Cox, Bimbi, } \\
\text { Parsons }\end{array}$ & I would not be willing to date a bisexual person. \\
\hline $\begin{array}{l}\text { Cox, Bimbi, } \\
\text { Parsons }\end{array}$ & I would be highly concerned if my current partner self-identified as bisexual \\
\hline $\begin{array}{l}\text { Cox, Bimbi, } \\
\text { Parsons }\end{array}$ & $\begin{array}{l}\text { I would be highly concerned if my partner revealed that in the past they had dated people who are a different } \\
\text { gender than myself. }\end{array}$ \\
\hline Ochs & I would accept a family member/friend who came out to me as bisexual. \\
\hline Alarie \& Gaudet & It is possible for someone to be romantically and/or sexually attracted to more than one gender \\
\hline Eisner & It is possible for someone to love despite gender \\
\hline Eisner & It is possible for one to love individuals first and genders second \\
\hline Hartman & Individuals can be open to sexual or emotional exploration with more than one gender \\
\hline Hartman & $\begin{array}{l}\text { I would describe individuals who are attracted to multiple genders as "going through a phase" or otherwise } \\
\text { temporarily attracted to multiple genders }\end{array}$ \\
\hline Hartman & People who profess attraction to multiple genders are speaking truthfully \\
\hline Ochs & Bisexuality is a legitimate sexual orientation \\
\hline Alarie \& Gaudet & There is no such thing as a bisexual: they are confused about whether they are really gay or straight. \\
\hline Mohr \& Rochlen & $\begin{array}{l}\text { Men cannot be bisexual: they just have not accepted that they are gay/are not comfortable with their sexuality } \\
\text { and use the title as an easier transition. }\end{array}$ \\
\hline Alarie \& Gaudet & $\begin{array}{l}\text { Women claim to be bisexual only for the attention of men or to experiment before/while engaging in sexual } \\
\text { activity with a man }\end{array}$ \\
\hline Hartman & Bisexuality is a phase that changes once a person decides to partner with a man or a woman \\
\hline Alarie \& Gaudet & $\begin{array}{l}\text { It is not possible for one person to truly be attracted to more than one gender: monosexuality is a superior } \\
\text { orientation/the default }\end{array}$ \\
\hline Hartman & In order for a person to be bisexual, they must be dating/sleeping with a man and a woman at the same time \\
\hline Alarie \& Gaudet & Bisexuals are inherently greedy. \\
\hline Obradors-Campos & A person must have sexual contact with both genders in order to qualify as bisexual. \\
\hline
\end{tabular}

Table 1 (continued)

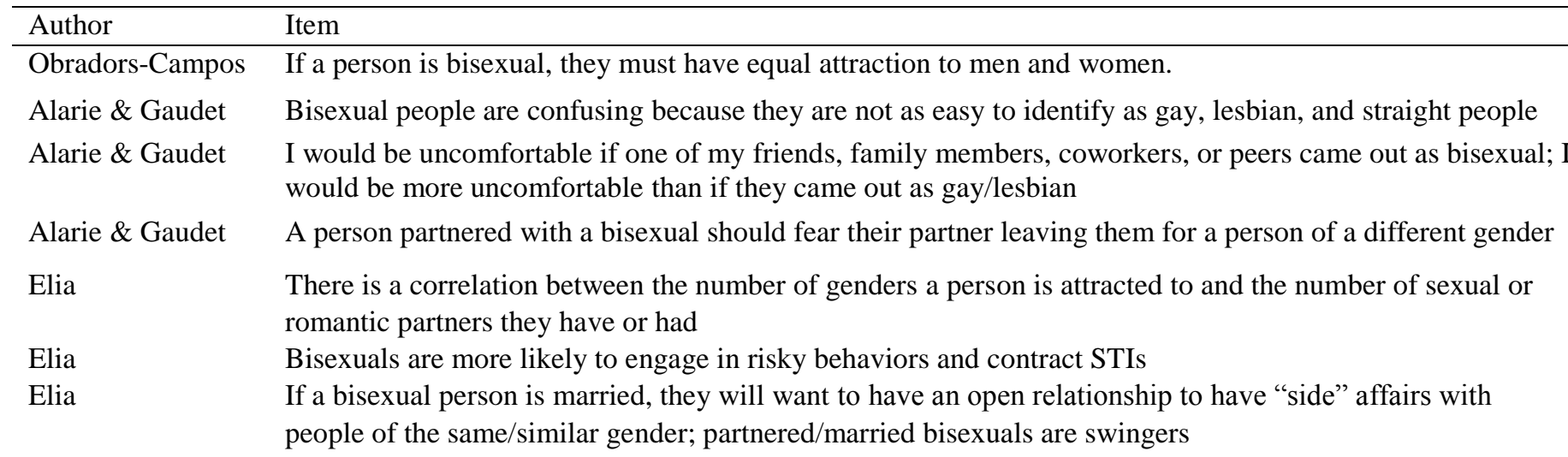


Mohr \& Rochlen

Ochs

Alarie \& Gaudet

See \& Hunt

See \& Hunt

Ochs

Obradors-Campos

Elia
Bisexuality is moral

Bisexuality is an acceptable lifestyle

Bisexuality is a threat to the heterosexual lifestyle.

Bisexuality is a threat to the LGBT movement.

I am critical of the bisexual community.

a relationship wherein one or more partner(s) is attracted to multiple genders can be as fulfilling as a relationship in which both partners are attracted to one gender

Bisexuals have "passing privilege" when they are in relationships with an opposite/different gender person I don't believe that bisexual people experience as much oppression as gay, lesbian, or transgender people do, if any 
Table 2

Biphobia and Bisexual Attitudes According to Gender and Sexual Orientation

\begin{tabular}{lccc}
\hline \multicolumn{1}{c}{ Identity Category } & $n$ & Biphobia Scale & Bisexual Attitudes Scale \\
& & $m(s d)$ & $m(s d)$ \\
\hline Gender & 161 & $73.02(17.06)$ & $69.03(14.35)$ \\
Male & 305 & $71.73(19.37)$ & $66.46(15.45)$ \\
Female & 5 & $64.81(20.61)$ & $61.86(17.36)$ \\
Other gender & & & $69.66(15.64)$ \\
Sexual Orientation & 332 & $75.63(19.59)$ & $63.83(11.61)$ \\
Heterosexual & 35 & $67.1(14.4)$ & $61.28(12.28)$ \\
Gay/Lesbian & 101 & $62.94(11.72)$ & $55.46(8.12)$ \\
Bi/Plurisexual & 5 & $52.4(6.58)$ & \\
Asexual & 5 & & \\
\hline
\end{tabular}


Table 3

Post hoc

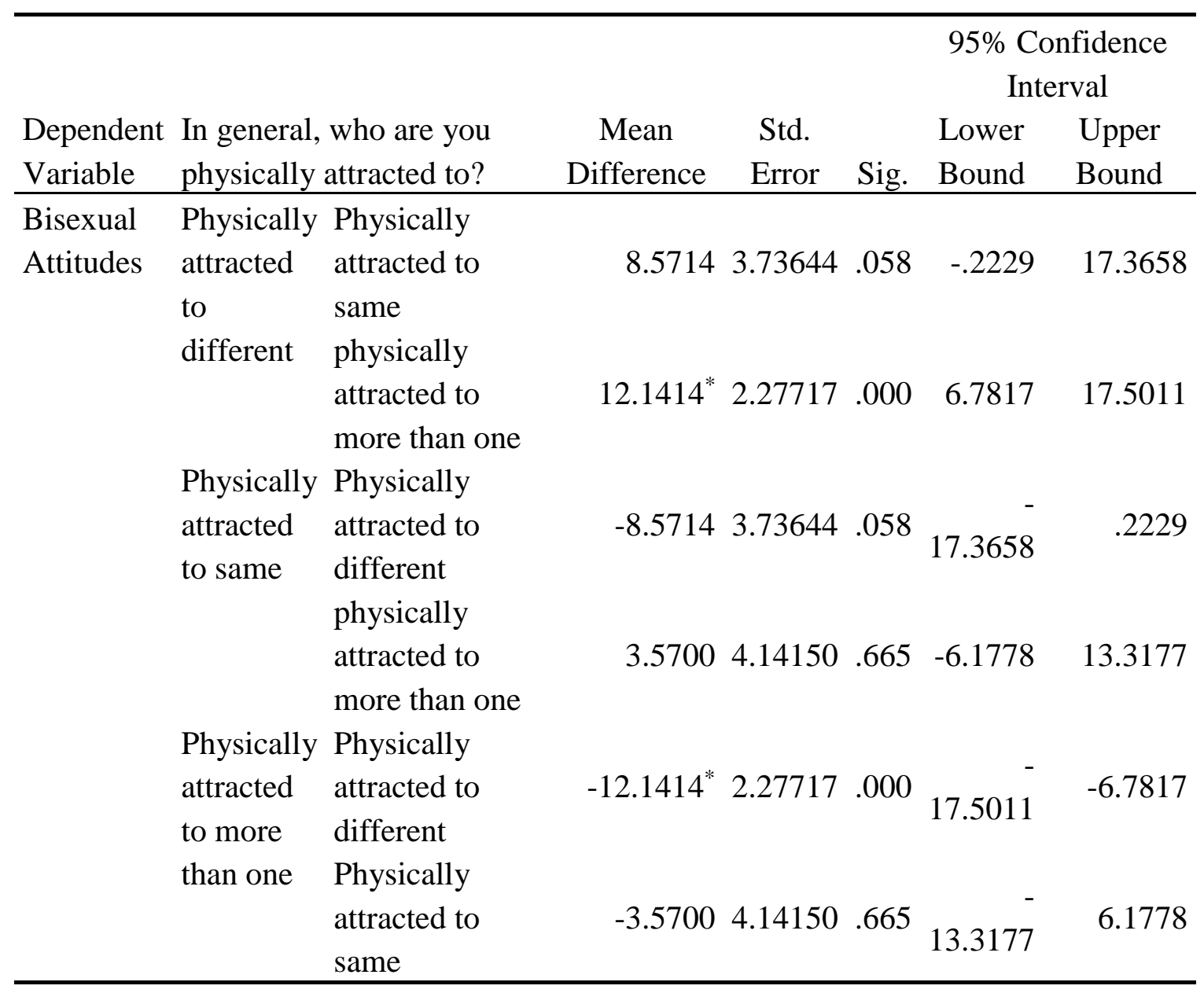


Table 3

Post hoc (continued)

95\% Confidence

Interval

\begin{tabular}{|c|c|c|c|c|c|c|c|}
\hline $\begin{array}{l}\text { Dependent } \\
\text { Variable }\end{array}$ & \multicolumn{2}{|c|}{$\begin{array}{l}\text { In general, who are you } \\
\text { physically attracted to? }\end{array}$} & $\begin{array}{r}\text { Mean } \\
\text { Difference }\end{array}$ & $\begin{array}{r}\text { Std. } \\
\text { Error }\end{array}$ & Sig. & $\begin{array}{l}\text { Lower } \\
\text { Bound }\end{array}$ & $\begin{array}{l}\text { Lower } \\
\text { Bound }\end{array}$ \\
\hline \multirow[t]{6}{*}{ Biphobia } & \multirow{2}{*}{$\begin{array}{l}\text { Physically } \\
\text { attracted } \\
\text { to } \\
\text { different }\end{array}$} & $\begin{array}{l}\text { Physically } \\
\text { attracted to } \\
\text { same }\end{array}$ & $11.4835^{*}$ & 4.40599 & .026 & 1.1133 & 21.8538 \\
\hline & & $\begin{array}{l}\text { physically } \\
\text { attracted to } \\
\text { more than } \\
\text { one }\end{array}$ & $16.6784^{*}$ & 2.68523 & .000 & 10.3582 & 22.9985 \\
\hline & \multirow[t]{2}{*}{$\begin{array}{l}\text { Physically } \\
\text { attracted } \\
\text { to same }\end{array}$} & $\begin{array}{l}\text { Physically } \\
\text { attracted to } \\
\text { different }\end{array}$ & $-11.4835^{*}$ & 4.40599 & .026 & 21.8538 & -1.1133 \\
\hline & & $\begin{array}{l}\text { physically } \\
\text { attracted to } \\
\text { more than } \\
\text { one }\end{array}$ & 5.1949 & 4.88365 & .537 & -6.2996 & 16.6894 \\
\hline & \multirow{2}{*}{$\begin{array}{l}\text { Physically } \\
\text { attracted } \\
\text { to more } \\
\text { than one }\end{array}$} & $\begin{array}{l}\text { Physically } \\
\text { attracted to } \\
\text { different }\end{array}$ & $-16.6784^{*}$ & 2.68523 & .000 & 22.9985 & -10.3582 \\
\hline & & $\begin{array}{l}\text { Physically } \\
\text { attracted to } \\
\text { same }\end{array}$ & -5.1949 & 4.88365 & .537 & 16.6894 & 6.2996 \\
\hline
\end{tabular}

Based on observed means.

The error term is Mean Square $($ Error $)=378.549$.

$* p<.05$. 